\title{
Soluble Factors from the Olfactory Bulb Attract Olfactory Schwann Cells
}

\author{
King Lok Liu,' Meng Inn Chuah, ${ }^{2}$ and Kenneth K. H. Lee' \\ 'Department of Anatomy, Chinese University of Hong Kong, Shatin, N.T., Hong Kong and 'Department of Anatomy, \\ University of Tasmania, Hobart, Tasmania, Australia 7001
}

\begin{abstract}
Olfactory Schwann cells (OSCs) extend processes that ensheathe bundles of olfactory axons as they course from the olfactory epithelium to the olfactory bulb (OB). Results of morphological and immunohistochemical studies have led to speculation that OSCs may be involved in guiding the olfactory axons to their target tissue. In this study we have explored this possibility by investigating the relationship between OSCs and the OB. Olfactory Schwann cells labelled with $1,1^{\prime}$-dioctadecyl $3,3,3^{\prime}, 3^{\prime}$-tetramethylindocarbocyanine perchlorate (Dil) were injected into the nasal region of E14 rat embryos and entire embryos were cultured for $24 \mathrm{hr}$. It was found in some embryos, that the OSCs had migrated toward the presumptive OB. Cocultures of neonatal OB explants on OSC monolayers showed that the OSCs were attracted to the $O B$ and formed a ring-like aggregate around the explant after $48 \mathrm{hr}$ culture. This attraction was absent when a piece of cerebrum was used in place of the OB. When medium conditioned by neonatal OBs was placed in the lower compartment of the chemotaxis chamber, OSCs seeded in the upper compartment migrated through the pores of the nucleopore filter to reach the underside which was in contact with the conditioned medium. After $6 \mathrm{hr}$ of incubation, scanning electron microscopy was performed on the underside of the nucleopore filters. Cell counts of OSCs showed that the cell density was significantly higher when medium conditioned by OBs was used instead of unconditioned medium or medium conditioned by cerebrum. The results of these experiments show that the OSCs migrate toward the $O B$ under the influence of soluble factor(s) secreted by the target tissue.
\end{abstract}

[Key words: olfactory Schwann cells, olfactory bulb, development, migration, olfactory axon, soluble factors]

One of the major issues in neurobiological research is the question of how axons are able to find their way and make synapses with the correct target during development. In the rat primary olfactory pathway, olfactory neurons (ONs) first extend axons into the underlying lamina propria at E14 (Farbman and Squinto, 1985). These axons are accompanied by cells which migrate

\footnotetext{
Received Nov. 15, 1993; revised July 27, 1994; accepted Aug. 5, 1994.

This work was supported by UPGC Grant 220401850 awarded to M.I.C. and K.K.H.L. and the United College Student Campus Work Scheme. We thank C. $\mathrm{Au}$, W.C. Lui, and M. Stranger for technical assistance, and Drs. S. Weston and C. Hinrichsen for the immunostaining protocol.

Correspondence should be addressed to Meng Inn Chuah, University of Tasmania, Department of Anatomy, G.P.O. Box 252C, Hobart, Tasmania, Australia 7001.

Copyright (C) 1995 Society for Neuroscience $0270-6474 / 95 / 150990-11 \$ 05.00 / 0$
}

out of the epithelium and move toward the rostral end of the cerebral vesicle. It has been shown in early mouse embryos that cells migrating from the medial side of the olfactory placode contain luteinizing hormone-releasing hormone (LHRH) and these cells eventually take up residence in the hypothalamus (Schwanzel-Fukuda and Pfaff, 1989; Wray et al., 1989). Other migrating cells become olfactory Schwann cells (OSCs) and some of them eventually distribute in the outer nerve layer of the olfactory bulb (OB) (Doucette, 1989; Chuah and Au, 1991; Norgren et al., 1992).

To avoid confusion, it should be noted that the OSCs are also known by the term "ensheathing cells" in some previously published reports (e.g., Devon and Doucette, 1992; Miragall and Dermietzel, 1992; Ramon-Cueto and Nieto-Sampedro, 1992; Goodman et al., 1993, Chuah and $\mathrm{Au}, 1994)$. The rcason for this dual terminology is that although OSCs bear some similarities with Schwann cells of other peripheral nerves, they are not identical to the latter. One notable difference is that the OSCs are derived from precursor cells in the olfactory placode and not from the neural crest (Chuah and $\mathrm{Au}, 1991$ ). They are present in the olfactory nerve layer of the $\mathrm{OB}$ and contribute to the formation of a glia limitans there (Doucette, 1990). In contrast, Schwann cells normally fail to penetrate into CNS structures, much less contribute to the formation of glia limitans.

The apparent role of neuroglial cells in guiding axon growth during ontogeny (Hatten, 1990; Silver et al., 1993) and in determining the success or failure of axonal regeneration in other nervous tissues (Anderson and Turmaine, 1986; Berry et al., 1988; Villegas-Perez et al., 1988; Savio and Schwab, 1989) has raised questions about whether the unique continual growth of axons in the adult primary olfactory pathway is related to the biology of the OSCs in this tissue. The OSCs do not myelinate or ensheathe individual axons. Instead they grow processes to ensheathe bundles of axons (Cuschieri and Bannister, 1975; Farbman and Squinto, 1985; Burd, 1991). In addition to the close spatial relationship between OSCs and olfactory axons, OSCs are known to express certain neurite-promoting molecules such as laminin and the neural cell adhesion molecule (N-CAM) (Liesi, 1985; Miragall et al., 1988, 1989). It has been shown that N-CAM, N-cadherin, and Ll mediate ON neurite outgrowth on astrocyte monolayers (Chuah et al., 1991). Recent studies in our laboratory show that interaction between membrane molecules are similarly involved in promoting olfactory neurite growth on OSC monolayers (Chuah and Au, 1994). Hence it is not surprising that several researchers have speculated on the role that OSCs may play in guiding the olfactory axons to their appropriate target, the OB (Cancalon, 1986; Barber and Dahl, 1987; Doucette, 1990; Goodman et al., 1993). 
The studies reported here are an attempt to address this question. We have investigated whether OSCs respond to external directional cues and the possible source of these signals. Experimental evidence from the whole embryo cultures, explant cultures and cell cultures in chemotaxis chamber is consistent with the notion that OSCs migrate toward the $\mathrm{OB}$ in response to soluble trophic factors released specifically by the bulb.

\section{Materials and Methods}

\section{Purification of olfactory Schwann cells}

Highly enriched cultures of OSCs ( $>96 \%$ purity) were purified from neonatal Sprague-Dawley rats according to the method developed by Chuah and Au (1993). Briefly, the method involved peeling away the olfactory nerve layer from the rest of the $O B$ and subjecting the layer to $0.25 \%$ trypsin and $0.03 \%$ collagenase digestion to dissociate cells. Contaminating cells, such as fibroblasts, were eliminated by treatment with $2.5 \times 10^{-7} \mathrm{M}$ cytosine arabinoside (Sigma, St. Louis, MO) and immunoadsorption with anti-Thy 1.1 antibodies (Serotec, Indianapolis, IN). Astrocytes originally present in the olfactory nerve layer were effectively removed from the OSCs during passaging by taking advantage of their greater adhesivity to plastic. The identity of the OSCs derived from this purification method has been previously confirmed ultrastructurally (Chuah and $\mathrm{Au}, 1993$ ). Final steps in the procedure included the addition of bovine pituitary extract (Sigma, St. Louis, MO), at a final concentration of $12 \mu \mathrm{g} / \mathrm{ml}$ to the culture medium (CM1) to stimulate division of OSCs. CM1 consisted of Dulbecco's modified Eagle's medium (DMEM, GIBCO, Grand Island, NY), supplemented with 10\% fetal bovine serum, MEM-Vitamin and penicillin/streptomycin.

\section{DiI labeling of olfactory Schwann cells}

1,1'-Dioctadecyl-3,3,3',3'-tetramethylindocarbocyanine perchlorate (DiI, Molecular Probe, Eugene, OR), a fluorescent lipophilic dye was used to label the OSCs. The dye is not toxic and does not alter the behavior or physiological properties of cells (Honig and Hume, 1986). A stock solution of the label was prepared by dissolving $4 \mathrm{mg}$ of DiI crystals in 1 $\mathrm{ml}$ of $100 \%$ ethanol. The labeling was achieved by adding some of the stock into the CMl (final concentration $40 \mu \mathrm{g} / \mathrm{ml}$ of Dil) containing the OSCs. After $1 \mathrm{hr}$ of incubation, the cells were washed three times in fresh CM1 to remove all of the excess unbound dye. The labeled OSCs were then trypsinized from the flask and used in experiments.

\section{Embryo cultures}

Manipulation of embryos. E14 rat embryos were obtained from pregnant Sprague-Dawley females by cervical dislocation. The day at which a vaginal plug was found was designated El. In prewarmed phosphate buffer medium, the decidual tissues and parietal membrane were removed from the embryos. A slit was then made in the yolk sac and amniotic cavity to expose the embryo. The survival of the operated embryos was enhanced by avoiding, as much as possible, damage to the major blood vessels on the surface of the yolk sac.

Approximately 500-1000 DiI-labeled OSCs were injected into the craniofacial region of the embryos using a pulled glass pipette. The labeled cells were introduced unilaterally in a frontal view of the embryo. Because of the translucence of the cmbryonic tissue, the OSCs can be placed consistently medial to the olfactory epithelium in the vicinity of the rostral half of the olfactory pit. A total of 10 embryos randomly taken were immediately processed for light microscopy ( $0 \mathrm{hr}$ culture) to demonstrate the site of injection. As an additional control, indian ink (Pelikan, \#17) was also introduced in a similar manner in a few embryos.

Immediately after surgery, the embryos that were to be cultured, were transferred individually into $50 \mathrm{ml}$ bottles containing $5 \mathrm{ml}$ of culture medium (CM2). CM2 consisted of 3 parts DMEM and 1 part rat serum (extracted from the blood of adult Sprague-Dawley rats). The bottles were inserted into a roller-incubator (BTC Engineering, UK) rotating at $20-40 \mathrm{rpm}$ and maintained at $37^{\circ} \mathrm{C}$. The cultures were gassed every $6 \mathrm{hr}$ with $95 \% \mathrm{O}_{2}$ and $5 \% \mathrm{CO}_{2}$.

Processing of embryos. Embryos that were injected with indian ink were fixed in Bouin's fixative and processed for routine light microscopy. Seven micrometer thick sections were made from these specimens and stained with hematoxylin and eosin. All other embryos (after $0 \mathrm{hr}, 6$ $\mathrm{hr}$, or $24 \mathrm{hr}$ of culture), which were injected with DiI-labeled OSCs, were fixed overnight in $4 \%$ paraformaldehyde. To trace the olfactory axons, a solution of 4-(4-dihexadecylaminostyryl)- $\mathrm{N}$-methylpyridinium iodide (DiA, Molecular Probe, Eugene, OR) at a concentration of $5 \mathrm{mg}$ / $\mathrm{ml}$ methanol was injected into the nasal pit to label the olfactory epithelium. The complete labeling of ONs and axons took approximately 4-5 d. The embryos were then decapitated and the heads immersed in $30 \%$ sucrose solution for $2 \mathrm{hr}$. The specimens were cryosectioned at 20 $\mu \mathrm{m}$ and examined under a Zeiss fluorescence microscope.

\section{Cocultures of explants on DiI-labeled olfactory Schwann cell monolayer}

DiI-labeled OSCs $\left(1.5 \times 10^{4}\right)$ were seeded onto each $12 \mathrm{~mm}$ diameter acetone washed, sterile glass coverslip. After $24 \mathrm{hr}$, the OSCs had attached and differentiated and were ready for use as a substratum for explant cultures.

Explants were obtained from 1-3 d old Sprague-Dawley rats. They were either the $\mathrm{OB}$ or a superior portion of the cerebrum of comparable size whose meningeal covering had been removed. The olfactory nerve layer of the OB was stripped off to remove most of the OSCs. This was verified by immunohistochemical staining of $12 \mu \mathrm{m}$ thick cryosections of some OBs, before and after removal of the olfactory nerve layer. Sections were incubated overnight at $4^{\circ} \mathrm{C}$ in mouse monoclonal antibody against NGF low affinity receptor (NGF-rec, 1:50), which labels OSCs but not astrocytes. The NGF-rec antibody was a generous gift from Dr. M. Shipley. The streptavidin-biotin-HRP technique and DAB were used to visualize the OSCs. Results of immunohistochemical staining showed that most of the OSCs of the OB were removed together with the olfactory nerve layer when it was peeled off (Fig. 1a,b). Hence, only a very small number of OSCs was left on the remainder of the $O B$ and they are unlikely to complicate interpretation of the results.

The OB or cerebral explants were placed onto the center of the OSC monolayer and enough CM1 was added to cover them. After $48 \mathrm{hr}$ of growth at $37^{\circ} \mathrm{C}$ and $100 \%$ humidity in an atmosphere of $5 \% \mathrm{CO}_{2}$, the entire cocultures were fixed in $4 \%$ paraformaldehyde for $10 \mathrm{~min}$. The explants were then gently removed with a pair of fine forceps and the coverslips with the adherent OSC monolayer were overturned onto glass slides and examined under a Zeiss fluorescence microscope.

\section{Chemotaxis chamber experiments}

Preparation of conditioned media. Olfactory bulb and cerebrum conditioned media were produced conventionally by organ culture as described by Chuah and Farbman (1983). Bricfly, five nconatal (1-3 d old) rat OBs (without olfactory nerve layer) or pieces of cerebrum (without meningeal covering) were placed on a piece of Millipore filter (Millipore, Bedford, MA) of $0.2 \mu \mathrm{m}$ pore size supported by a triangular stainless steel grid inside a Falcon organ culture dish (Becton Dickinson, Lincoln Park, NJ). One milliliter of CMl was added to the dish and the set up was maintained for $5 \mathrm{~d}$ at $37^{\circ} \mathrm{C}$ in an atmosphere of $5 \% \mathrm{CO}_{2}$. Following this period of culture, the resulting conditioned media were frozen, thawed and centrifuged at $1800 \mathrm{rpm}$ for $10 \mathrm{~min}$ to remove possible contaminating cells. The conditioned media were then used at full strength.

Preparation of rat dermal fibroblasts. The procedure used was modified from the method by Ham (1980). A newborn Sprague-Dawley rat was killed by decapitation and a piece of skin was dissected from its back. It was cut into small pieces of about $1 \mathrm{~mm}^{3}$ in phosphate buffered saline. About 10 of these pieces were transferred to each $25 \mathrm{~cm}^{2}$ Falcon flask (Becton Dickinson, Lincoln Park, NJ). They were placed with the hypodermis side facing the surface of the flask to enhance fibroblast outgrowth from the explants. Sufficient CMI was added to prevent detachment and dehydration of the explants. Five days after, when numerous fibroblasts had migrated out, the remaining explants were discarded. By careful monitoring of trypsinization, the less adherent fibroblasts can be separated from the rest of the epithelial cells in the flask. The fibroblasts were seeded into a new flask and the purity determined by immunostaining for fibronectin $(>95 \%)$.

Chemotaxis experiments. We have investigated the response of the OSCs to soluble molecules present in media conditioned by $O B$ and cerebrum. The response of fibroblasts to possible chemoattractants in media conditioned by $O B$ was also investigated. The experiments were conducted using the blind well chemotaxis chambers (Nuclepore, Cambridge, MA) (Fig. 2). The apparatus is made up of an upper and a lower compartment separated by a nucleopore filter (12 $\mu \mathrm{m}$ pore size, Nuclepore, Cambridge, MA) that has been precoated with fibronectin (100 

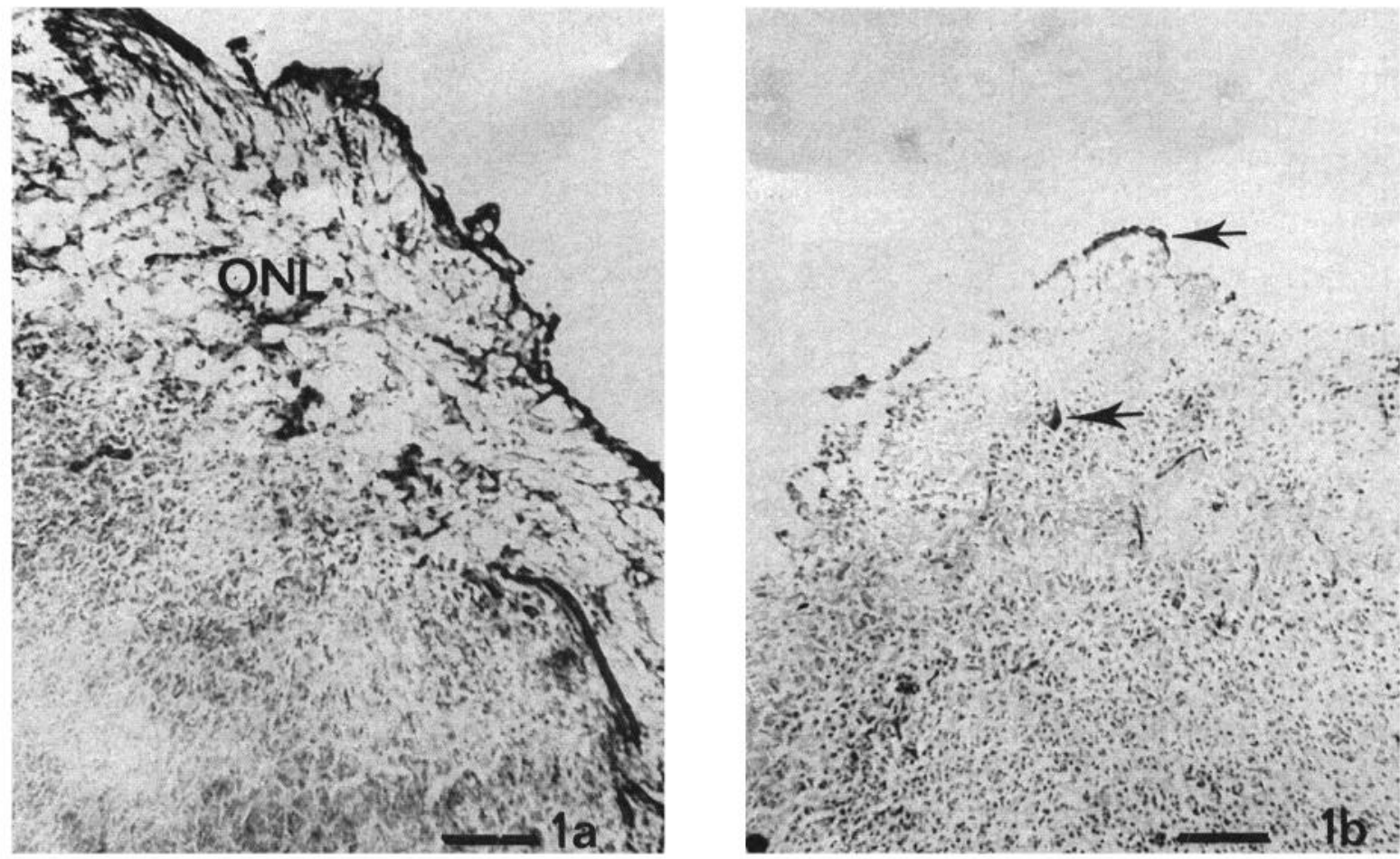

Figure 1. a, Neonatal rat olfactory bulb immunostained for the low affinity NGF receptor. Positive immunoreactivity denoting the presence of olfactory Schwann cells is found predominantly in the olfactory nerve layer $(O N L)$. $b$, Neonatal rat olfactory bulb with the olfactory nerve layer peeled off. Immunoreactivity for the low affinity NGF receptor is reduced drastically, being present in a few scattered cells (arrows). Scale bars, $150 \mu \mathrm{m}$.

$\mu \mathrm{g} / \mathrm{ml}$ of human plasma fibronectin, Sigma, St. Louis, MO). Cells are seeded into the upper compartment and if they are responsive to the reagents in the lower compartment, they will migrate through the pores in the filter and settle on the underside of the membrane facing the chemoattractant.

There were three groups of experiments: (1) OSCs in the upper compartment and $\mathrm{OB}$ conditioned or unconditioned (CM1) medium in the lower compartment, (2) OSCs in the upper compartment and cerebrum conditioned or unconditioned (CM1) medium in the lower compartment, and (3) fibroblasts in the upper compartment and $\mathrm{OB}$ conditioned or unconditioned (CM1) medium in the lower compartment. The aim of the first group of experiments was to determine whether or not the OB was secreting a chemoattractant(s) which acted on OSCs. The second group of experiments determined whether the source of the chemoattractant(s) was specific to the OB or if it could also be present in other neural tissues such as the cerebrum. The last group of experiments was

\section{Blind Well Chemotaxis Chamber}

Figure 2. A diagrammatic illustration

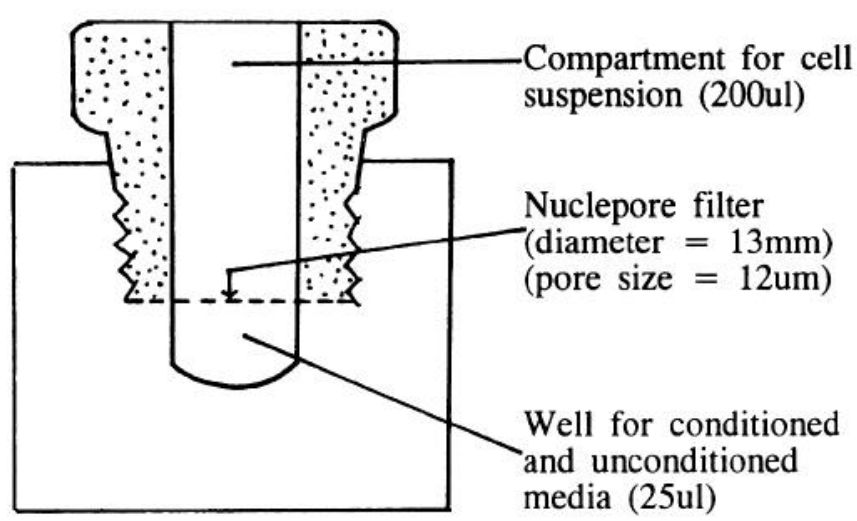
of a blind well chemotaxis chamber. The chamber is separated into two compartments by a nucleopore filter. In the upper compartment is placed the cell suspension and in the lower the test solution. 
designed to ascertain whether the trophic substance(s) produced by the OB could attract cells other than OSCs.

In all experiments, $25 \mu \mathrm{l}$ of conditioned or unconditioned medium was introduced into the lower compartment of the chemotaxis chamber. The fibronectin coated filter was placed over it and held securely by a screw retainer. Olfactory Schwann cells or fibroblasts suspended in 200 $\mu 1$ of CM1 $\left(5.6 \times 10^{4}\right.$ cells $\left./ \mathrm{ml}\right)$ were then introduced into the upper compartment. Lastly, the whole assembly was incubated for $6 \mathrm{hr}$ at $37^{\circ} \mathrm{C}$ in an atmosphere of $5 \% \mathrm{CO}_{2}$

Following incubation, the filters were removed from the chambers, fixed in $2.5 \%$ glutaraldehyde and processed for scanning electron microscopy. Briefly, the procedure included post fixation in $0.1 \%$ osmium tetroxide, dehydration through an ascending series of alcohol, and final processing through a series of Freon 113 of increasing concentration. The specimens were then critical point dried and coated with palladium gold. They were viewed in a Jeol JSM-35CF scanning electron microscope. Micrographs were taken of an area measuring $0.2 \mathrm{~cm}^{2}$ in the center of the filter and the number of cells were counted directly on the micrographs at a magnification of $830 \times$.

\section{Results}

\section{Embryo cultures}

Cryo- and paraffin sections of the E14 rat embryos which were fixed immediately following injections of DiI-labeled OSCs or indian ink, showed that the OSCs had been injected approximately at the same site from one embryo to another (Fig. 3). Growing olfactory axons were absent in this region and there was little tissue damage to the surrounding mesenchyme.

A total of 23 embryos were cultured for $24 \mathrm{hr}$ while 2 were cultured for $6 \mathrm{hr}$. After this period, viability was determined by the presence of heart beat and well developed vascularization. Two embryos did not survive. The rest were processed and the heads cryosectioned serially.

Under $515 \mathrm{~nm}$ (fluorescein isothiocyanate) filter illumination, the DiA-labeled olfactory epithelium and axons were bright yellow while the DiI-labeled OSCs were barely visible. When $580 \mathrm{~nm}$ (rhodamine) filter illumination was used, the DiI-labeled OSCs gave an intense orange-red color while the DiA olfactory epithelium appeared dull red. Therefore by viewing the specimens under illumination of different wavelengths, the structures can be unambiguously identified.

The DiI-labeled OSCs injected into the rat embryos differentiated into a spindly bipolar morphology. The original injection site was usually obscured following culture because the wound created by the pulled glass pipette was very small and tissue recovery was particularly efficient in the embryos. In both specimens examined after $6 \mathrm{hr}$ of culture, OSCs were found migrating out of the injection site toward the general direction of the OB (Fig. $4 a$ ). After $24 \mathrm{hr}$ culture, 18 out of the 21 surviving embryos showed that the DiI-labeled OSCs had migrated and some were in contact with outgrowing axons. These OSCs had their long axes aligned parallel to the direction of the axons. The finding that the labeled OSCs had migrated to the growing olfactory nerves was not particularly surprising because we had observed in vitro that OSCs seeded in proximity with each other often tended to migrate toward each other (unpublished observations). It is conceivable that migration of the DiI-labeled OSCs was a result of the homotypic attraction to the other OSCs accompanying the newly growing axons.

Out of these 18 embryos, 8 of them contained additional DiIlabeled OSCs which had migrated in the direction of the presumptive $\mathrm{OB}$ (Fig. $4 b-d$ ). Those in the leading edge had migrated over a distance of more than $150 \mu \mathrm{m}$ in $24 \mathrm{hr}$. Observations of successive sections indicated that these OSCs were not associated with the olfactory nerves which were growing from the

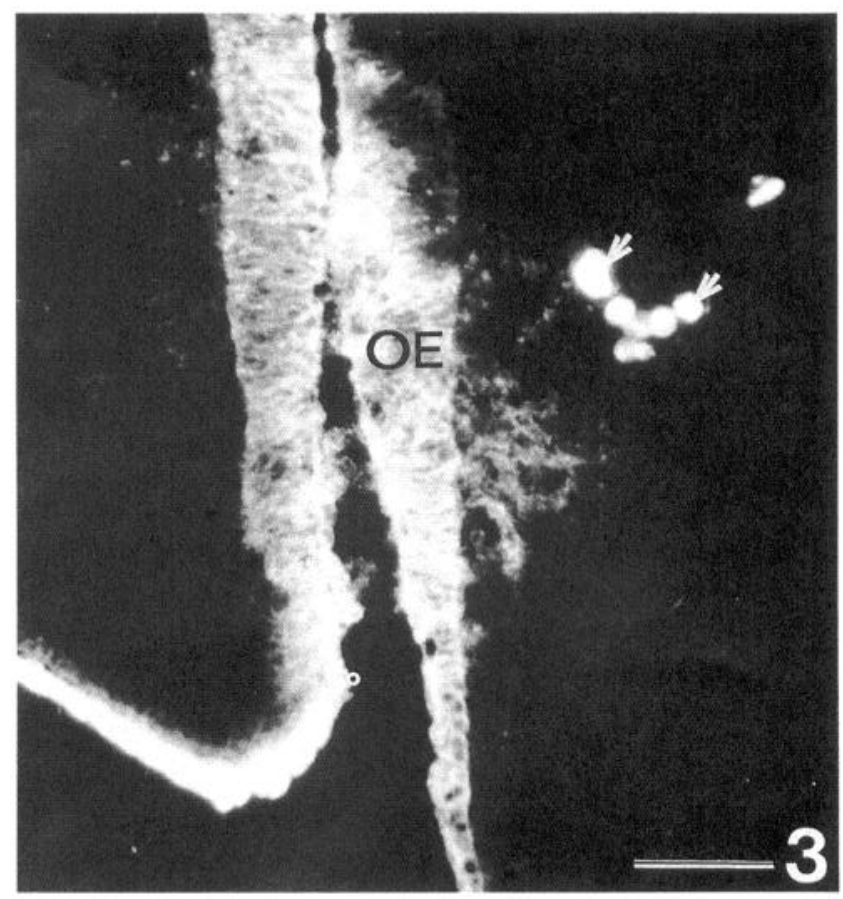

Figure 3. A representative specimen showing the location of DiI-labeled olfactory Schwann cells (arrows) immediately after their injection into the E14 rat embryos. The olfactory epithelium $(O E)$ has been previously labeled with DiA fluorescent dye. Scale bar, $50 \mu \mathrm{m}$.

epithelium. This preliminary finding hinted that the OB could be attracting the OSCs by some unknown mechanism. To explore the possibility of a trophic factor(s) mediating this attraction, cocultures of $\mathrm{OB}$ explants and OSC monolayers were conducted.

In 3 out of 21 embryos, the DiI-labeled OSCs remained in the mesenchyme, showing movement in no particular direction after $24 \mathrm{hr}$ of culture. It could not be determined with certainty the distance through which these cells might have migrated because the original injection site was not apparent. It is possible that in these cases, the OSCs had been introduced at a site slightly too distant to be influenced by the OB or OSCs associated with the olfactory nerves.

\section{Cocultures of explants on DiI-labeled olfactory Schwann cell monolayer}

Following $48 \mathrm{hr}$ culture, the $\mathrm{OB}$ or cerebrum explants were removed and observations under the fluorescence microscope were made on the DiI-labeled OSCs adherent on the coverslips. The placement pattern of the OSCs on the coverslips which originally had OBs was strikingly different from that of the coverslips bearing the cerebrum explants. In 23 out of 27 cocultures of OB on OSC monolayer, the ECs had aggregated to form a dense ring around where the $\mathrm{OB}$ was originally placed (Fig. 5a). The ring was sometimes about 10 cells thick and immediately external to it was a region of relatively low OSC density (Fig. $5 b, c$ ). In contrast, the OSCs surrounding the cerebral explant were evenly distributed and no dense ring of OSCs was ever observed (Fig. $6 a, b$ ). The results thus suggested two possibilities: (1) the OB could be secreting a trophic factor(s) which attracted OSCs and which was not produced by the cerebrum; (2) cells on the periphery of the OB explant, and not 


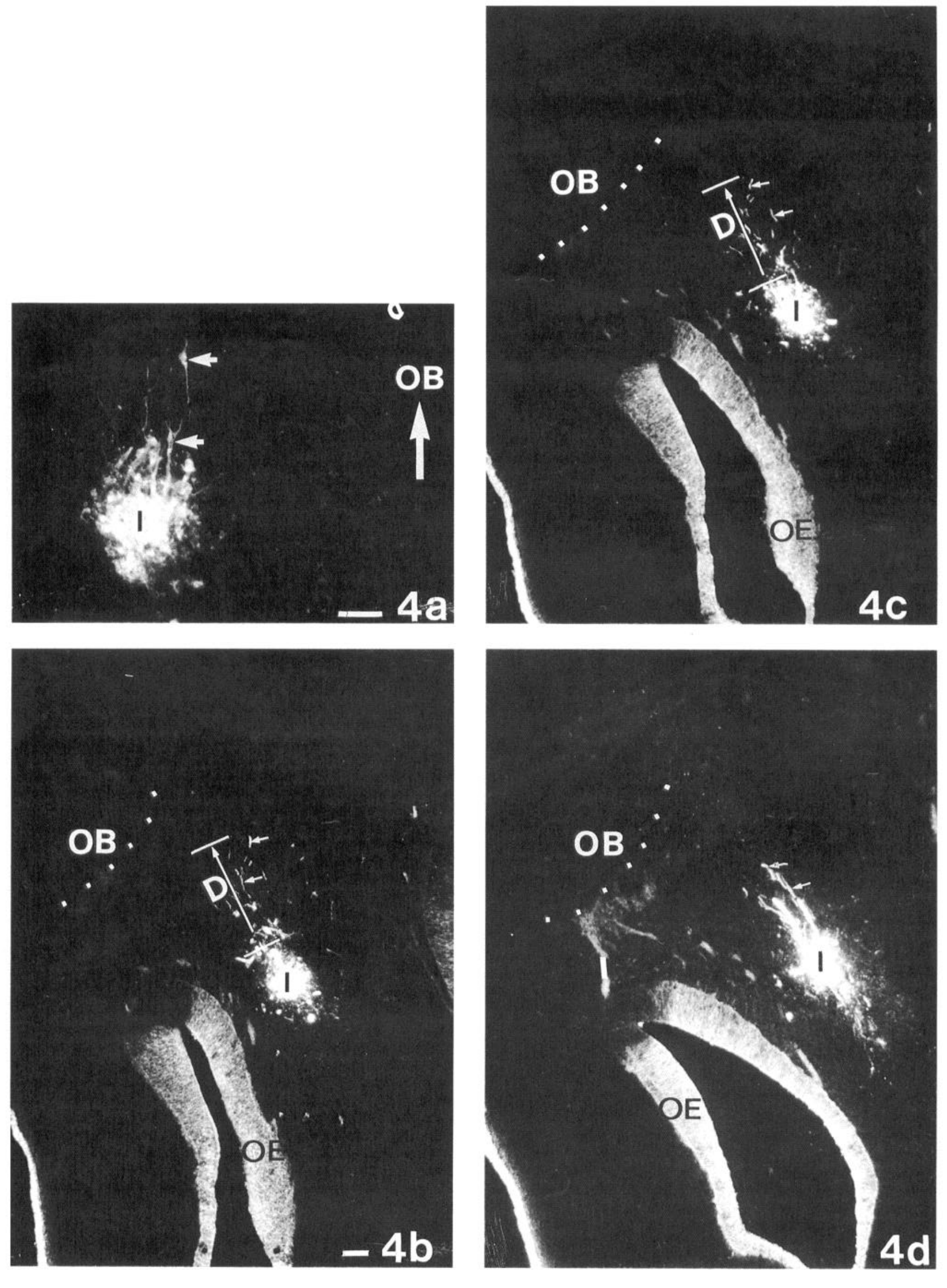



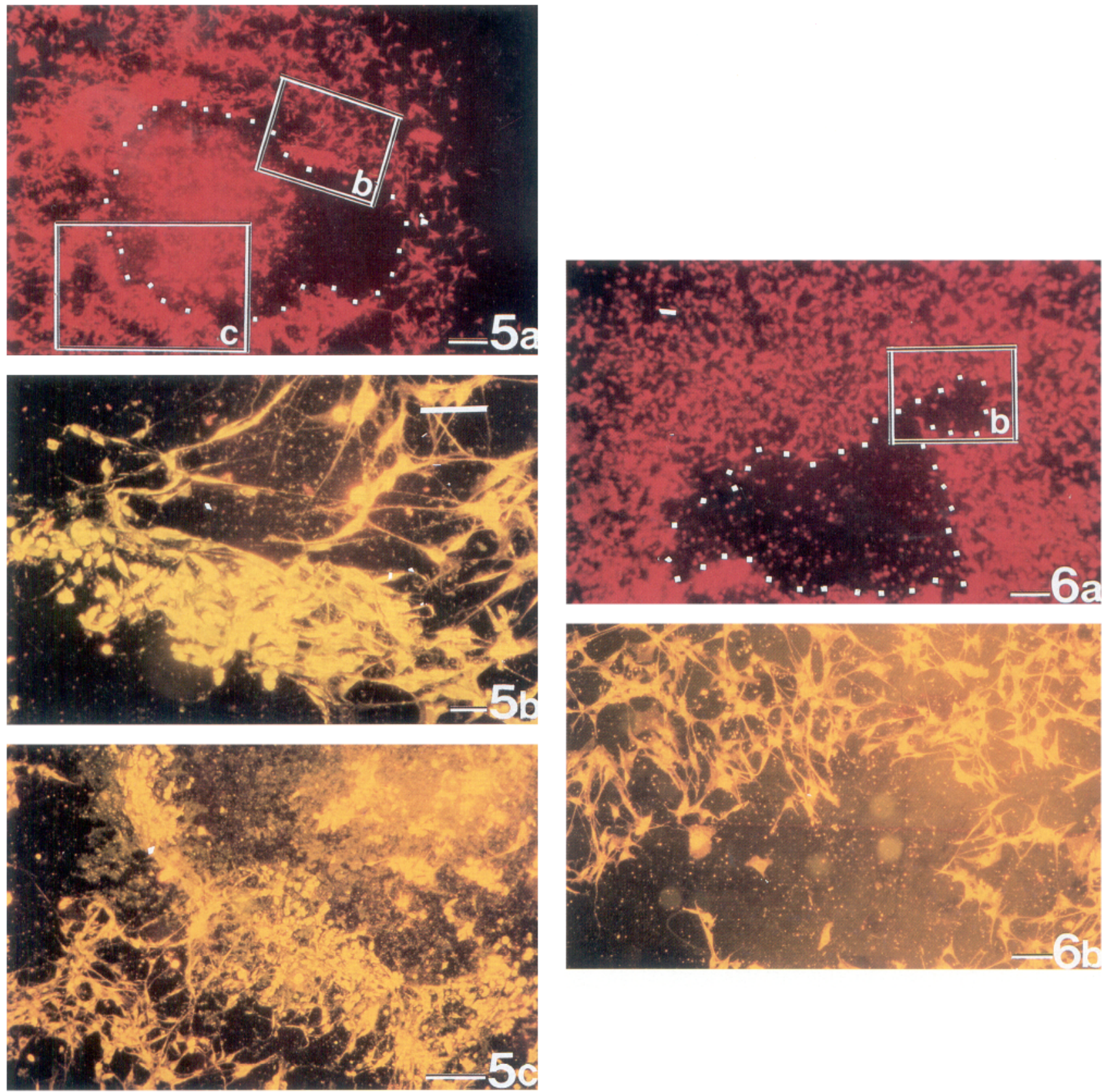

Figure 5. Fluorescence micrograph. $a$, An overview of DiI-labeled olfactory Schwann cells cocultured with an olfactory bulb explant. The explant has been removed, and the dotted line indicates its original position. $b$, A high power magnification of a framed region in $a$ showing aggregation of olfactory Schwann cells around the periphery of the explant. Specimen is viewed under a rhodamine filter. $c$, Framed region in $a$, again demonstrating olfactory Schwann cells accumulating at the borders of the explant. Scale bars: $a, 400 \mu \mathrm{m} ; b, 50 \mu \mathrm{m} ; c, 100 \mu \mathrm{m}$.

Figure 6. Fluorescence micrograph. $a$, An overview of DiI-labeled olfactory Schwann cells cocultured with a piece of cerebrum. The dotted line indicates the position of the cerebrum before it was removed. $b$, High power magnification of framed region in $a$. In contrast to olfactory Schwann cells grown in the presence of an olfactory bulb, the olfactory Schwann cells are not aggregated but are instead evenly spread around the borders of the cerebrum. Specimen is viewed under a rhodamine filter. Scale bars: $a, 400 \mu \mathrm{m} ; b, 100 \mu \mathrm{m}$.

Figure 4. Cryosections of embryos injected with DiI-labeled olfactory Schwann cells and cultured for $6 \mathrm{hr}$ and $24 \mathrm{hr}$. $a$, A representative 6 hr specimen. Olfactory Schwann cells (arrows) are beginning to migrate out of the injection site $(I)$. The olfactory bulb (OB) is out of view and is located superiorly as indicated by the large arrow. $b$-d are representative sections from $24 \mathrm{hr}$ specimens. Spindle-shaped olfactory Schwann cells (arrows) continue to migrate away from the implantation site $(I)$ toward the olfactory bulb $(O B$, dotted lines). $O E$, DiA-labeled olfactory epithelium. $D$ indicates the extent of migration. Magnification of $b-d$ is the same. Scale bars: $a, 40 \mu \mathrm{m} ; b, 50 \mu \mathrm{m}$. 

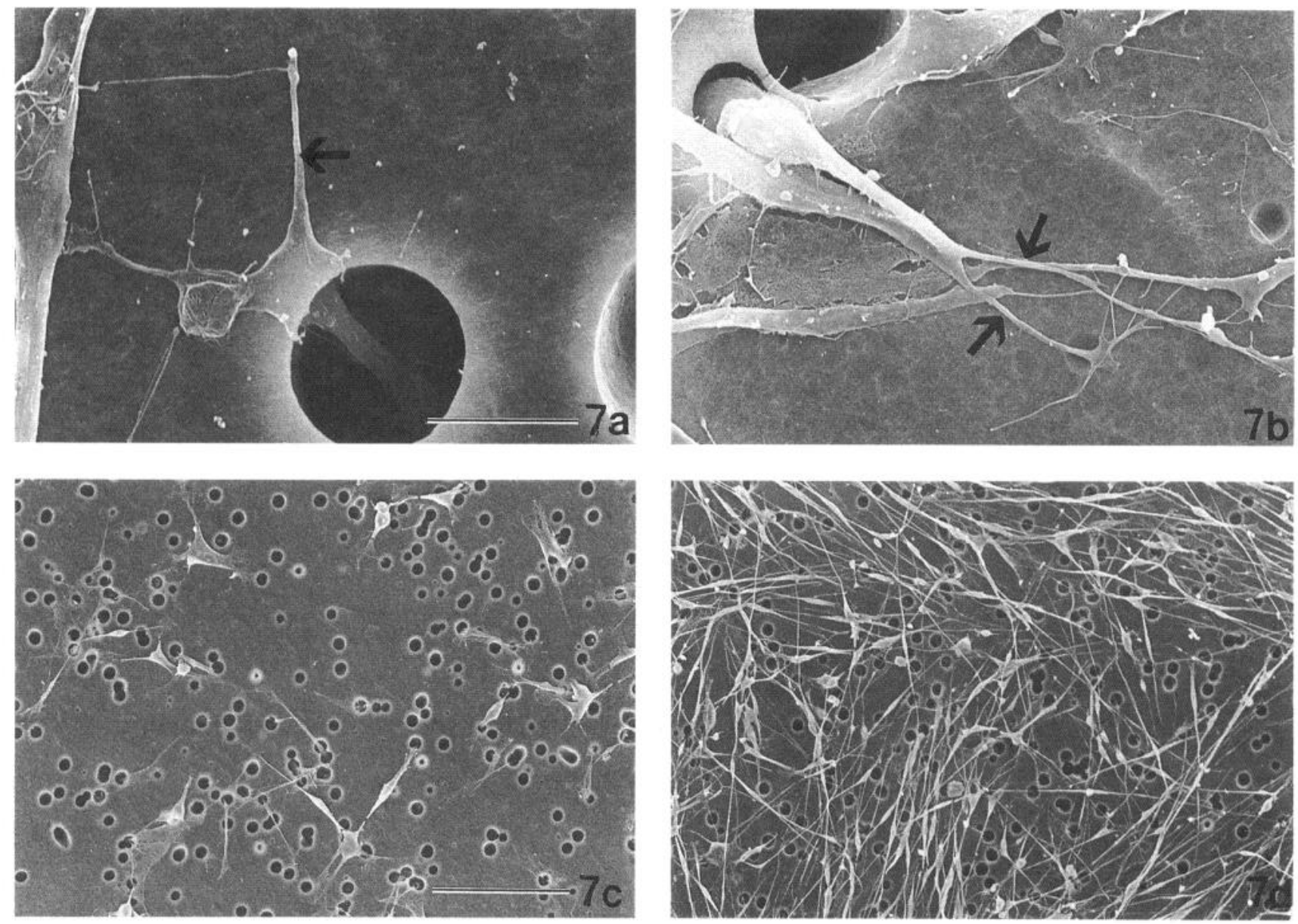

Figure 7. Scanning electron micrographs of the undersides of nucleopore filters (surface directly facing the lower compartment of the blind well chamber) obtained $6 \mathrm{hr}$ after the plating of olfactory Schwann cells $\left(5.6 \times 10^{4}\right)$. Twenty-five microliters of olfactory bulb conditioned $(a, b, d)$ or unconditioned $(c)$ media were added to the lower chamber. $a$ and $b$ show successive stages of olfactory Schwann cells migrating through the 12 $\mu \mathrm{m}$ pores in the nucleopore membrane. The olfactory Schwann cells migrate by sending long slender processes through the pores (arrows). Scale bar, $10 \mu \mathrm{m}$. $c$, In unconditioned medium, very few olfactory Schwann cells are found on the underside of the filters. In contrast, the number of olfactory Schwann cells is increased dramatically in the presence of olfactory bulb conditioned medium $(d)$. Scale bar, $100 \mu \mathrm{m}$.

the cerebrum, expressed selective adhesion molecules for OSCs. Hence, randomly migrating OSCs which happened to contact the $\mathrm{OB}$ explant became attached to the tissue. The experiments utilizing the chemotaxis chambers were able to provide more insight and determine which of the two explanations was more likely.

In the four cocultures of $\mathrm{OB}$ and $\mathrm{OSC}$ monolayer which failed to result in a directional migration of OSCs, the OBs were detached from the substratum. Consequently, it was likely that in these cultures no concentration gradient of the trophic factor(s) was established and therefore the OSCs failed to demonstrate directional migration.

\section{Chemotaxis experiments}

Scanning electron microscopy of the underside of the nucleopore filters showed the typical spindly largely bipolar morphology of the OSCs. Successive stages of OSCs migrating through the pores were observed (Fig. $7 a, b$ ). The OSCs initially extended their growth cone bearing filopodia-like processes through the pore before the cytoplasmic process followed through (Fig. 7a). The migration of the entire cell body was observed soon after (Fig. $7 b$ ). The OSCs were morphologically different from the fibroblasts which were used in the third group of chemotaxis exper- iments. The fibroblasts were polygonal and bigger in size with a diameter of about $12 \mu \mathrm{m}$. They also tended to flatten and cell boundaries were less distinct compared to those of OSCs.

Figures 8-10 summarize the results of the cell counts on the underside of the nucleopore filters in the three groups of experiments. In the presence of $\mathrm{OB}$ conditioned medium, there were significantly more OSCs on the underside of the nucleopore filters than that in the control chamber (Fig. $7 c, d$ ). The mean density of $813 \pm 34 \mathrm{OSCs} / \mathrm{mm}^{2}$ nucleopore filter in the chambers containing $\mathrm{OB}$ conditioned medium was nearly threefold greater than the control value of $270 \pm 41$ (Fig. 8). This finding argues strongly that the $\mathrm{OB}$ secretes soluble factor(s) which attracts OSCs. The aggregation of a ring of OSCs around OB explants (see Cocultures of explants on DiI-labeled olfactory Schwann cell monolayer, above) was less likely to be a result of merely random migration of OSCs in a tissue culture dish. However, it is accepted that the findings thus far do not exclude the possibility that the cells of the OB could in fact also express selective adhesion molecules for OSCs.

Figure 9 shows that the OSC count was not significantly different in the presence of both cerebrum conditioned $(171 \pm 14)$ and unconditioned medium $(197 \pm 23)$ suggesting that the trophic factor(s) acting on the OSCs was specifically derived from 


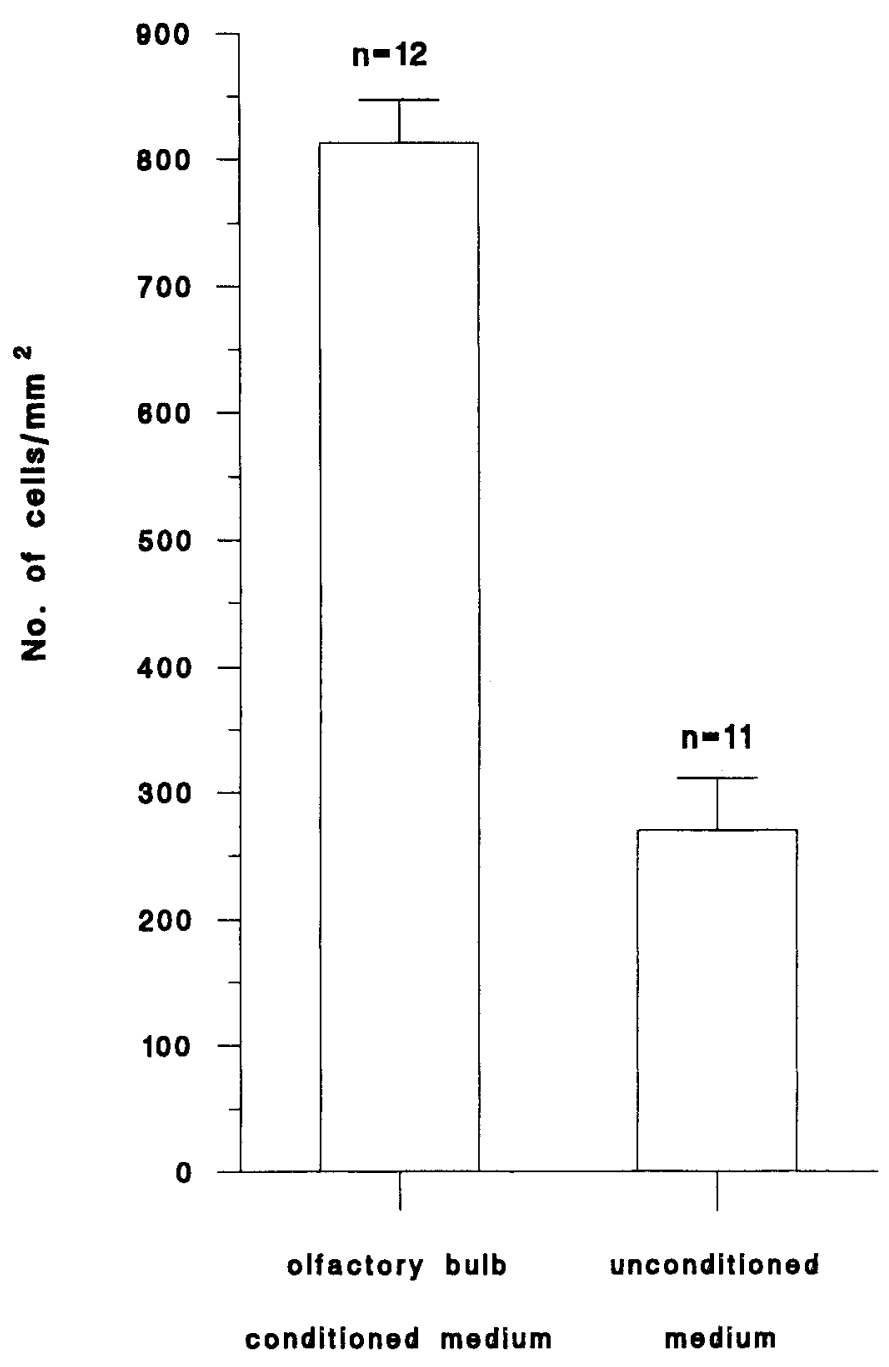

Figure 8. Average number of olfactory Schwann cells on the lower surface of nucleopore filters: olfactory bulb conditioned medium versus unconditioned medium. Significantly differenl al $P<0.0001$ by Student $t$ test. $N=$ number of filters examined.

the $\mathrm{OB}$. In addition, this trophic factor(s) did not influence the migration of fibroblasts because the mean number of fibroblasts on the underside of the nucleopore filters was rather similar in the $\mathrm{OB}$ conditioned $(75 \pm 10)$ and unconditioned medium (73 \pm 9) (Fig. 10).

\section{Discussion}

By conducting whole embryo culture, explant culture on OSC monolayers and chemotaxis experiments, we have shown that OSCs migrate toward the $\mathrm{OB}$ in response to a trophic factor(s) secreted by the OB. This factor(s) acts specifically on OSCs and is not produced by the cerebrum.

The finding that the OB secretes a trophic factor(s) which acts as a chemoattractant to OSCs has an important implication. It may be the crucial event in the understanding of the processes involved in olfactory axon path finding. Attempts to resolve this issue were first undertaken by researchers employing morphological and immunohistochemical techniques (e.g. Doucette, 1984, 1990; Vickland et al., 1991; Miragall and Dermietzel, 1992). The presence of N-CAM and L1 on OSC and olfactory axon surfaces gave rise to the oversimplified view that the OSCs

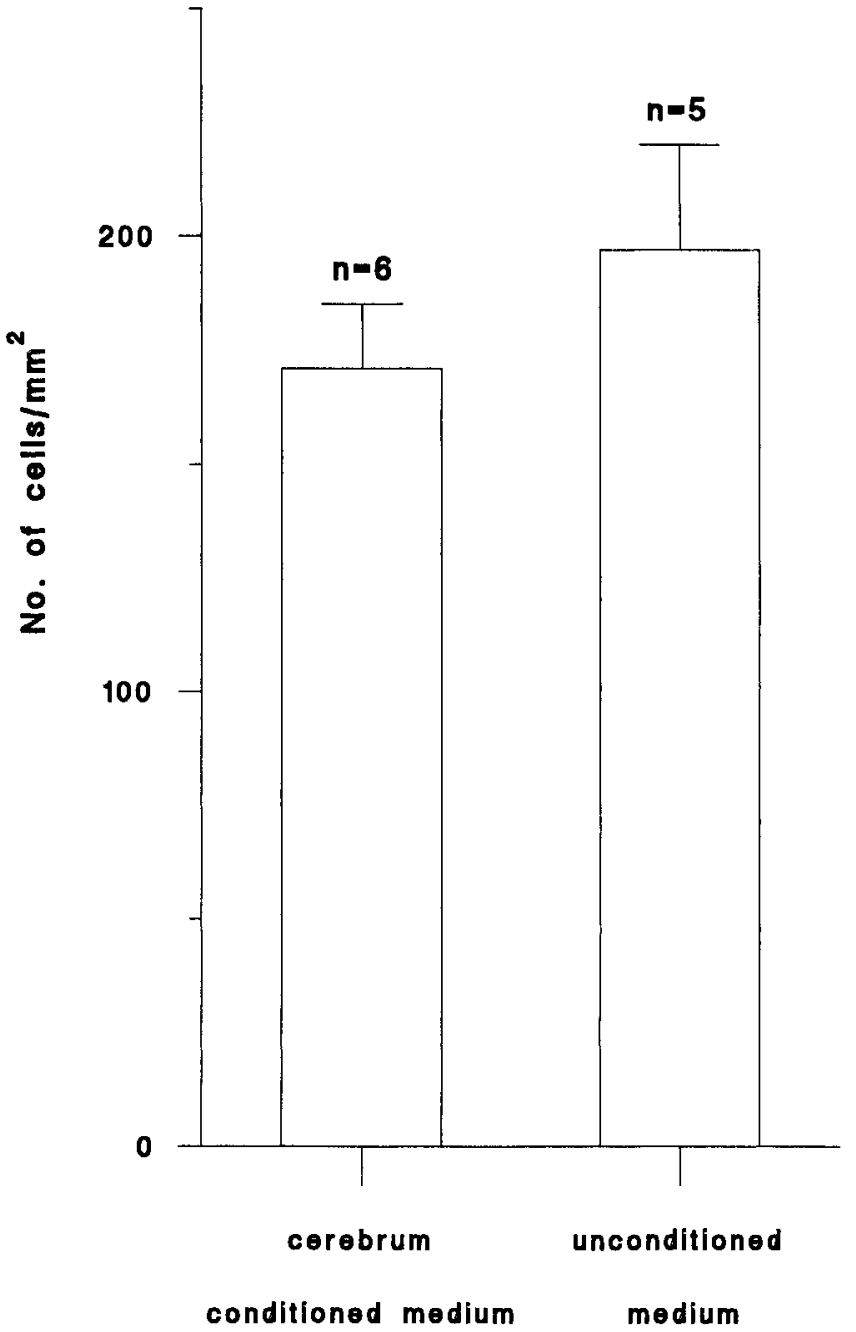

Figure 9. Average number of olfactory Schwann cells on the lower surface of nucleopore filter: cerebrum conditioned medium versus unconditioned medium. $P>0.05 . N=$ number of filters examined.

could be guiding the olfactory axons to their target by mere expression of adhesion molecules (Doucette, 1990). Furthermore, most studies have usually demonstrated the effect of trophic factors from target tissues on axonal growth of neurons (e.g., Chan and Haschke, 1981; Carri and Ebendal, 1987; Pini, 1993); little attention has been paid to their effect on the neuroglial cells.

Although this is the first report of migration of OSCs in response to trophic factor(s) from the OB, similar migration of other cell types unrelated to the nervous system is well documented (Grotendorst et al., 1981; Venkatasubramanian and Solursch, 1984; Devreotes and Zigmond, 1988). For example, neutrophils have specific receptors for certain peptides and they migrate up a concentration gradient of these peptides (Devreotes and Zigmond, 1988). Venkatasubramanian and Solursch (1984), in an in vitro study, demonstrated that embryonic skeletal muscle cells migrate toward a gradient of platelet-derived growth factor present in the serum.

In the PNS, Schwann cells are known to migrate proximaldistally into the premuscle mass of the chick limb bud before axon ingrowth (Noakes and Bennett, 1987). However, the signal which triggers this migration is still unknown. If the Schwann 


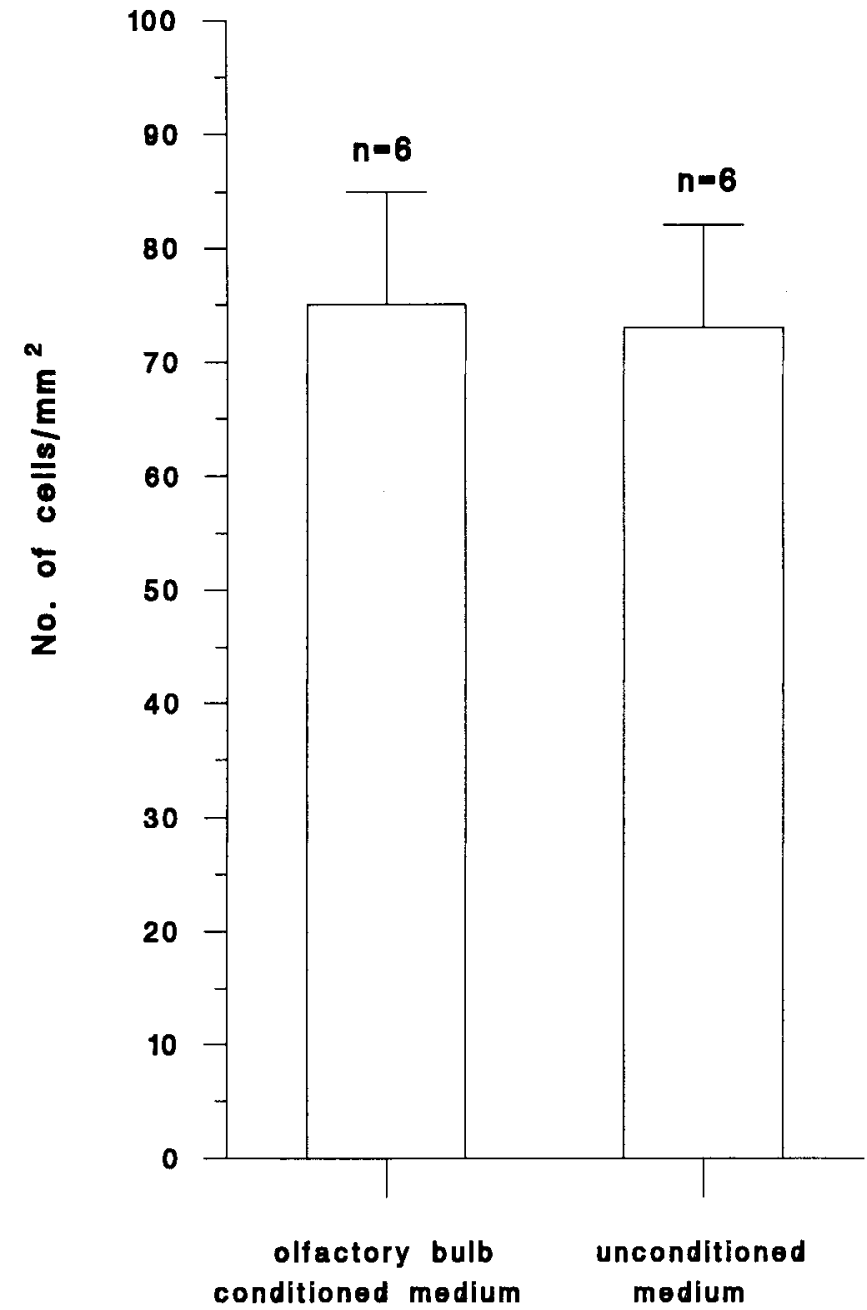

Figure 10. Average number of fibroblasts on the lower surface of nucleopore membrane: olfactory bulb conditioned medium versus unconditioned medium. $P>0.05 . N=$ number of filters examined.

cells are eliminated by removal of ncural crest cells before they migrate out, the spinal nerves will grow into the base of the limb, but they fail to extend far enough to make normal connections with the muscles (Carpenter and Hollyday, 1986). In an earlier study in which Carney and Silver (1983) described the developing distal auditory pathway in the mouse embryo, they showed the presence of a group of neural crest-derived funnel cells between the developing otocyst and the auditory ganglion. It was proposed that the funnel cells provided an adhesive substrate and influenced the directional growth of the auditory axons to the otocyst.

In the CNS, evidence showing the correlation between growing axons and migrating neuroglial cells has been reported recently in an immunohistochemical and morphological study (Silver et al., 1993). Silver and his coworkers demonstrated that during cerebral hemispheric fusion, there is remodeling of the basal lamina which is associated with glial cells. Next, a glial "sling" forms at the corticoseptal junction which is followed closely by the invasion of fibers of the dorsal callosal stria. The spatiotemporal patterning suggests that the glial cells in this region may be imparting specific directional cues to the growing axons.

Immature glial cells have also been implicated in promoting

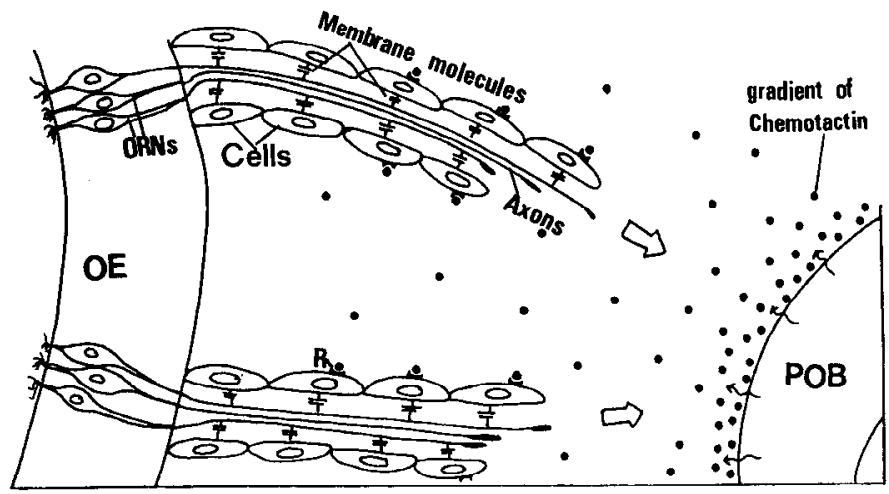

Figure 11. A hypothetical model illustrating how olfactory axons are guided to the presumptive olfactory bulb $(P O B)$ in E14-15 rat embryos. The POB secretes chemotactic factor(s) which diffuses, in the form of a gradient, toward the olfactory epithelium. The olfactory Schwann cell migrating out of the OE presumably bear receptors $(R)$ for these chemotactic molecules and are guided by them to migrate toward the POB. The olfactory Schwann cells in turn, express membrane molecules on their cell surface which promote the growth of olfactory axons.

regrowth of axons in injured central nervous tissues. Blaugrund and his coworkers showed that following nerve crush of the fish optic nerve, both mature and immature glial cells migrated to the injury site and subsequently, leading growth cones of the regenerating axons were found to be closely associated with the immature glial cells. In contrast, migration of glial cells into the injured area of the rat optic nerve was absent and they suggested that this might partially account for the failure of rat optic nerve to regenerate. In another study, immature astrocytes harvested on Millipore filters which were then transplanted into the brains of acallosal mice, were able to reduce glial scarring and promote axonal regeneration (Smith et al., 1986).

With the findings from our present and previous studies (Chuah and $\mathrm{Au}, 1991,1993$, 1994; Chuah et al., 1991), we put forward a proposal on the mechanism by which olfactory axons are guided toward the target OB (Fig. 11). During ontogeny, as the first olfactory axons perforate the basal lamina of the epithelium to enter the lamina propria, they are accompanied by a group of cells, possibly OSCs. The exact identity of these cells is uncertain because they have not been defined immunohistochemically; our previous studies demonstrated that they could only be stained for GFAP at E16 (Chuah and Au, 1991). On the other hand, in vitro studies in our laboratory show that ONs are able to extend axons on OSCs but fail to do so on noncellular substrata, even in the presence of medium conditioned by OSCs (Chuah and Au, 1994), suggesting that olfactory axon growth is mediated by molecular interaction between membrane surfaces of ONs and OSCs. The experimental evidence from this and earlier studies is consistent with the proposal that during development, directional guidance of the olfactory axons to the $\mathrm{OB}$ is provided by the migration of the OSCs in response to chemoattractant(s) released by the OB. Groups of cells, most likely OSCs, migrate out of the olfactory epithelium with the axons, and resemble a moving carpet on which the olfactory neurites grow (Fig. 11).

It is notable that in an earlier study by Gonzales and his colleagues (1985), in which they cocultured a fragment of an E16 rat $\mathrm{OB}$ in close proximity to a piece of olfactory mucosa of the same stage, they found that the $O B$ fragment failed to influence the direction of growth of olfactory axons. They also 
reported that no migrating cells from the olfactory epithelium was observed in their culture system. It is now known that many of these migrating cells are OSCs (Doucette, 1989; Chuah and $\mathrm{Au}, 1991)$ and the lack of directionality in axon growth could be attributed to the absence of OSCs in their in vitro system.

Our proposal on olfactory axonal pathfinding is probably more representative of the development of the primary olfactory pathway during ontogeny, that is, when the first axons and OSCs are growing through a "virgin" environment. The situation may be different in the postnatal animal when ONs are undergoing turnover and new ones are being produced by the basal cells (Levey et al., 1991; Mackay-Sim and Kittel, 1991). Axons of immature ONs will be growing through a connective tissue region which is already populated with mature axons and their OSCs. It has not been elucidated what type of effect the preexisting olfactory nerve fibers and their OSCs exert on the newly growing axons.

However, results of bulbectomy experiments (Graziadei et al., 1978, 1979; Graziadei and Samanen, 1980) do raise some speculations with regard to this possibility. After removal of an OB in the neonatal mouse, it is found that newly derived ONs send their axons through the cribriform plate, and in many cases, penetrate the cerebral forebrain and synapse with the neurons there (Graziadei et al., 1978, 1979). At the same time, the forebrain is found to protrude into the void left by the removal of the OB. One interpretation is that the forebrain may be secreting a chemoattractant(s) similar to that of the OB. However results of our cerebral explant cultures on OSC monolayers suggest otherwise. What is unknown is the fate of the OSCs previously associated with the olfactory nerve fibers which have been severed as a consequence of bulbectomy. One wonders, if following axonal degeneration and cell death, these OSCs remain in their original location in the connective tissue, and thereby act as a preformed bridge for guiding new axons into the cranium. Similarly, in normal turnover of ONs in postnatal animals, there could be other sources of directional cue for growing olfactory axons in addition to the $\mathrm{OB}$.

This study represents the first report of OSCs migrating in response to a trophic factor(s) released by the $\mathrm{OB}$. Future areas of research will include investigating the biochemical nature and other possible functions of this secretion.

\section{References}

Anderson PN, Turmaine M (1986) Pcripheral ncrve regencration through grafts of living and freeze-dried CNS tissue. Neuropathol Appl Neurobiol 12:389-399.

Barber PC, Dahl D (1987) Glial fibrillary acidic protein (GFAP)-like immunoreactivity in normal and transected rat olfactory nerve. Exp Brain Res 65:681-685.

Berry M, Rees L, Hall S, Yiu P, Silvers J (1988) Optic axons regenerated into sciatic nerve isografts only in the presence of Schwann cells. Brain Res Bull 20:223-231.

Blaugrund E, Lavie V, Cohen I, Solomon A, Schreyer DJ, Schwartz M (1993) Axonal regeneration is associated with glial migration: comparison between the injured optic nerves of fish and rats. J Comp Neurol 330:105-112.

Burd GD (1991) Development of the olfactory nerve in the african clawed frog, Xenopus lacvis. I. Normal development. J Anat 304:123134.

Cancalon PF (1986) Role of Schwann cells in olfactory nerve regeneration. J Cell Biol 103:A251.

Carney PR, Silver J (1983) Studies on cell migration and axon guidance in the developing distal auditory system of the mouse. J Comp Neurol 215:359-369.

Carpenter EM, Hollyday M (1986) Defective innervation of the chick limbs in the absence of presumptive Schwann cells. Soc Neurosci Abstr 12:1210.

Carri NG, Ebendal T (1987) Target field specificity in the induction of retinal neurite outgrowth. Dev Brain Res 31:83-90.

Chan KY, Haschke RH (1981) Action of a trophic factor(s) from rabbit corneal epithelial culture on dissociated trigeminal neurons. J Neurosci 1:1155-1162.

Chuah MI, Au C (1991) Olfactory Schwann cells are derived from precursor cells in the olfactory epithelium. J Neurosci Res 29:172180.

Chuah MI, Au C (1993) Cultures of ensheathing cells from neonatal rat olfactory bulbs. Brain Res 601:213-220.

Chuah MI, Au C (1994) Olfactory cell cultures on ensheathing cell monolayers. Chem Senses 19:25-34.

Chuah MI, Farbman AI (1983) Olfactory bulb increases marker protein in olfactory receptor cells. J Neurosci 3:2197-2205.

Chuah MI, David S, Blaschuk O (1991) Differentiation and survival of rat olfactory epithelial neurons in dissociated cell culture. Dev Brain Res 60:123-132.

Cuschieri A, Bannister LH (1975) The development of the olfactory mucosa in the mouse: electron microscopy. J Anat 119:471-498.

Devon R, Doucette R (1992) Olfactory ensheathing cells myelinate dorsal root ganglion neurites. Brain Res 589:175-179.

Devreotes P, Zigmond S (1988) Chemotaxis in eucaryotic cells. Annu Rev Cell Biol 4:649-686.

Doucette JR (1984) The glial cells in the nerve fiber layer of the rat olfactory bulb. Anat Rcc 210:385-391.

Doucette JR (1989) Development of the nerve fiber layer in the olfactory bulb of mouse embryos. J Comp Neurol 285:514-527.

Doucette R (1990) Glial influences on axonal growth in the primary olfactory system. Glia 3:433-449.

Farbman AI, Squinto LM (1985) Early development of olfactory receptor cell axons. Dev Brain Res 19:205-213.

Gonzales F, Farbman AI, Gesteland RC (1985) Cell and explant culture of olfactory chemoreceptor cells. J Neurosci Methods 14:77-90.

Goodman MN, Silver J, Jacobberger JW (1993) Establishment and neurite outgrowth properties of neonatal and adult rat olfactory bulb glial cell lines. Brain Res 619:199-213.

Graziadei PPC, Samanen DW (1980) Ectopic glomerular structures in the olfactory bulb of neonatal and adult mice. Brain Res 187:467472.

Graziadei PPC, Levine RR, Monti Graziadei GA (1979) Plasticity of connections of the olfactory sensory neuron: regeneration into the forebrain following bulbectomy in the neonatal mouse. Neuroscience 4:713-727

Graziadei PPC, Levine RR, Monti Graziadei GA (1987) Regeneration of olfactory axons and synapse formation in the forebrain after bulbectomy in neonatal mice. Proc Natl Acad Sci USA 75:5230-5234.

Grotendorst GR, Seppa HEJ, Kleinmann HK, Martin GR (1981) Attachment of smooth muscle cells to collagen and their migration towards platelet-derived growth factor. Proc Natl Acad Sci USA 78: 3669-3672.

Ham RG (1980) Dermal fibroblasts. In: Methods in cell biology, Vol 21A (Harris CC, Trump BF, Stoner GD, eds), pp 255-276. New York: Academic.

Hatten ME (1990) Riding the glial monorail: a common mechanism for glial-guided neuronal migration in different regions of the developing mammalian brain. Trends Neurosci 13:179-183.

Honig MG, Hume RI (1986) Fluorescent carbocyanine dyes allow living neurons of identified origin to be studied in long-term cultures. J Cell Biol 103:171-187.

Levey MS, Chikaraishi DM, Kauer JS (1991) Characterization of potential precursor populations in the mouse olfactory epithelium using immunocytology and autoradiography. J Neurosci 11:3556-3564.

Liesi P (1985) Laminin-immunoreactive glia distinguish regenerative adult CNS systems from non-regenerative ones. EMBO J 4:25052511.

Mackay-Sim A, Kittel P (1991) Cell dynamics in the adult mouse olfactory epithelium: a quantitative autoradiograph study. J Neurosci 11:979-984.

Miragall F, Dermietzel R (1992) Immunocytochemical localization of cell adhesion molecules in the developing and mature olfactory system. Microsc Res Tech 23:157-172.

Miragall F, Kadmon G, Husmann M, Schachner M (1988) Expression of cell adhesion molecules in the olfactory system of the adult mouse: presence of the embryonic form of N-CAM. Dev Biol 129:516-531. 
Miragall F, Kadmon G, Schachner M (1989) Expression of L1 and $\mathrm{N}-\mathrm{CAM}$ cell adhesion molecules during development of the mouse olfactory system. Dev Biol 135:272-286.

Noakes PG, Bennett MR (1987) Growth of axons into developing muscles of the chick forelimb is preceded by cells that stained with Schwann cell antibodies. J Comp Neurol 259:330-347.

Norgren RB Jr, Ratner N, Brackenbury R (1992) Development of olfactory nerve glia defined by a monoclonal antibody specific for Schwann cells. Dev Dynamics 194:231-238.

Pini A (1993) Chemorepulsion of axons in the developing mammalian central nervous system. Science 261:95-98.

Ramon-Cueto A, Nieto-Sampedro M (1992) Glial cells from adult rat olfactory bulb: immunocytochemical properties of pure cultures of ensheathing cells. Neuroscience 47:213-220.

Savio T, Schwab ME (1989) Rat CNS white matter, but not gray matter is nonpermissive for neuronal cell adhesion and fiber outgrowth. J Neurosci 9:1126-1133.

Schwanzel-Fukuda M, Pfaff DW (1989) Origin of luteinizing hormonereleasing hormone neurons. Nature 338:161-164.
Silver J, Edwards MA, Levitt P (1993) Immunocytochemical demonstration of early appearing astroglial structures that form boundaries and pathways along axon tracts in the fetal brain. J Comp Neurol $328: 415-436$

Smith GM, Miller RH, Silver J (1986) Changing role of forebrain astrocytes during development, regenerative failure, and induced regeneration upon transplantation. J Comp Neurol 251:23-43.

Venkatasubramanian K, Solursch M (1984) Chemotactic behaviour of myoblasts. Dev Biol 104:428-433.

Vickland H, Westrum LE, Kott JN, Patterson SL, Bothwell MA (1991) Nerve growth factor receptor expression in the young and adult rat olfactory system. Brain Res 565:269-279.

Villegas-Perez MP, Vidal-Sanz M, Bray GM, Aguayo AJ (1988) Influence of peripheral nerve grafts on the survival and regrowth of axotomized retinal ganglion cells in adult rats. J Neurosci 8:265-280.

Wray S, Nieburgs A, Elkabes S (1989) Spatiotemporal cell expression of luteinizing hormone-releasing hormone in the prenatal mouse: evidence for an embryonic origin in the olfactory placode. Dev Brain Res 46:309-318. 